\title{
Comprehensive Surgical Treatment as the Mainstay of Management in Retroperitoneal Sarcomas: Retrospective Study from Two Non-sarcoma Specialist Centers
}

\author{
ATHANASIOS PETROU ${ }^{1}$, ANASTASIA CONSTANTINIDOU ${ }^{2}$, MICHAEL KONTOS ${ }^{3}$, \\ ALEXANDROS PAPALAMPROS ${ }^{3}$, DEMETRIOS MORIS ${ }^{3}$, CHRIS BAKOYIANNIS $^{3}$, \\ KYRIAKOS NEOFYTOU ${ }^{1}$, GEORGE KOUROUNIS ${ }^{1}$ and EVANGELOS FELEKOURAS ${ }^{2}$ \\ ${ }^{1}$ Hepatobiliary and Surgical Oncology Department, Nicosia Teaching Hospital, Nicosia, Cyprus; \\ ${ }^{2}$ Divisions of Molecular Pathology and Cancer Therapeutics, The Institute of Cancer Research, London, U.K.; \\ ${ }^{3}$ First Department of Surgery, University of Athens Medical School, Laikon General Hospital, Athens, Greece
}

\begin{abstract}
Background/Aim: Complete resection, surgical expertise and individualization of patient management in comprehensive oncology centres result in better clinical outcomes in patients presenting with retroperitoneal sarcomas. Patients and Methods: Clinical outcomes of primary and recurrent retroperitoneal sarcoma resections performed between January 2002 and December 2016 in two large surgical oncology, but non-sarcoma specialist centers, were reviewed to determine the efficacy of complete surgical resection as the principle instrument for treatment. The histological type, tumor size and grade, as well as organ resection, were recorded and subsequently reviewed. Results: Our study included 108 cases of sarcoma resection (60 firsttime, 38 second-time and 10 third-time laparotomies) in 60 patients (35 males and 25 females). Most patients had complete resection: 57 had a macroscopically complete $(R 0 / R 1)$ resection and three had $R 2$ resection. The 90-day mortality rate was zero and morbidity was minimal. Fiveand 10-year overall survival (OS) rates were $88 \%$ and $79 \%$, respectively, whereas the corresponding disease-free survival (DFS) rates were 65\% and 59\%, respectively. High-grade tumors were associated with decreased DFS (hazard ratio $(H R)=3.35 ; 95 \%$ confidence interval $(C I)=1.23-9.10$; $p=0.018)$ and decreased $O S(H R=7.18 ; 95 \% C I=1.50-34.22$; $p=0.013)$. Conclusion: Complete surgical resection of retroperitoneal sarcomas combined with individualized patient management when offered by experienced surgical
\end{abstract}

Correspondence to: Demetrios Moris, MD, M.Sc., Ph.D., MACS, First Department of Surgery, University of Athens Medical School, Laikon General Hospital, Agiou Thoma 17, Goudi, Athens, Greece. E-mail: dimmoris@yahoo.com

Key Words: Retroperitoneal sarcoma, resection, long-term outcome. oncology teams, adhering to international guidelines, can succeed in providing patients with good long-term outcomes, comparable to those achieved at sarcoma-specialist centers.

Retroperitoneal sarcomas (RPS) are malignant neoplasms that account for $10-15 \%$ of all soft-tissue tumors (1-4). Histological tumor type, grade, location and extension of resection have been well-documented prognostic factors for long-term survival (5-7). On many occasions, other therapies may be used in the neoadjuvant setting, such as radiotherapy and occasionally chemotherapy before or after resection, with emerging evidence that these are associated with survival benefit in selected patients $(4,8-12)$.

The usually asymptomatic growth, as well as size and location of RPS, set many challenges for surgeons, primarily because the retroperitoneal space is anatomically complex but also because RPS often lack definitive boundaries for surgical compartmentalization. In the absence of randomized data, different surgical techniques have been used for the management of these tumors over the years, with a gradual shift towards more radical approaches (13). Simple tumor resection was replaced by en-bloc resection of the tumor with all involved surrounding organs and, more recently, compartmental resection of non-involved contiguous organs has been advocated in an attempt to ensure $\mathrm{R} 0$ resection and local disease control and, if possible, survival benefit (13-17).

Given the complex nature of RPS surgery, much emphasis has recently been placed on appropriate referring and management of these patients at specialist sarcoma centers in order to achieve improved short- and long-term outcomes $(18-20)$. Whilst this notion is entirely appropriate in most countries, there are countries (or remote areas within large countries) where the small number of new sarcoma cases annually does not justify the existence of centers specializing in sarcoma. 
In the present article, we report combined data of two large surgical oncology centers (one in Greece, one in Cyprus) on the surgical approach and survival of patients with RPS. Given that the number of new sarcoma cases presenting in these two countries each year is small, these cases are managed in a similar manner by general surgeons with experience in abdominal surgery of malignant tumors, including RPS. They are supported by a multidisciplinary oncology team, but not necessarily a sarcoma specialist team. The aim of the study was to assess whether the long-term outcomes of patients in non-specialist centers over a period of 15 years were comparable to those of patients treated at high-volume sarcoma centers.

\section{Patients and Methods}

Individual patient consent was obtained prior to initiation of the study. The study includes results of primary and recurrent retroperitoneal resections spanning over a period of 15 years, between January 2002 and December 2016. Cases not surgically treated were not included in the study. The operations were undertaken at the First Department of Surgery, University of Athens Medical School, Athens, Greece and at the Hepatobiliary and Surgical Oncology Department, Nicosia Teaching Hospital, Nicosia, Cyprus.

Each patient was evaluated for general health status and comorbidities. The screening process included a full cardiorespiratory evaluation, full blood count, liver function tests, urea and electrolytes and extensive imaging. The imaging profile included chest and abdominal X-rays, computerized tomography and magnetic resonance imaging, where appropriate. This was done to evaluate the exact location and size of the tumor and identify any possible metastases at staging. The cardiovascular, respiratory and urinary functions were kept in homeostasis, where necessary. The hospital-based multi-disciplinary team (MDT), consisting of surgeons, oncologists, radiologists and specialized nurses, evaluated each patient on the basis of these test results in order to determine if the patient was suitable for $\mathrm{R} 0$ resection.

The final decision and the surgical strategy were systematically based on parameters including tumor histology, extent of disease on imaging, patient's performance status and comorbidities. The possible surgical scenarios, the overall treatment plan and the potential need to proceed with adjunct procedures were decided at the MDT meetings. Where appropriate, assistance by experienced hepatobiliary, upper gastrointestinal and vascular surgeons was utilized to ensure the best possible outcomes. In order to reach a decision on how to operate, the MDT adhered to international guidelines on the management of sarcomas (4).

All patient records were retrospectively reviewed for tumor size, grade, location, histological type, duration of illness prior to presentation and surgery-related parameters including perioperative blood loss, operating theatre time and in-hospital stay. Information was also obtained about adjuvant therapies (chemotherapy and/or radiotherapy). Contiguous or complete organ resections were recorded.

Statistical analysis. Statistical analyses were performed using the Statistical Package of the Social Sciences (SPSS) version 17.0 (SPSS Inc., Chicago, IL, USA). The primary endpoints of the study were overall survival (OS) and disease-free survival (DFS). DFS was calculated from the date of operation to the date of relapse, and was censored at the time of death or at the time of last follow-up if the patient did not show any clinical or radiological features of tumor recurrence. OS was calculated from the date of operation to the date of disease-related death, and was censored at the time of last follow-up for patients that were alive or at the time of death from cause unrelated to the disease. Both OS and DFS were calculated for the cases undergoing first-time laparotomy (60 cases).

Chi-square test was used for calculating the association between clinicopathological characteristics and recurrence or disease-related death. The impact of clinicopathological characteristics on DFS and OS was analyzed using the Kaplan-Meier method. Survival outcomes between groups were compared with the log-rank test. A $p$-value of less than 0.05 was considered statistically significant. Because of the small number of patients in the study population, multivariate analysis was not performed.

\section{Results}

The mean patient age was 60 years (range $=36$ to 81 years). There were 60 patients representing 108 cases in total, 35 (58.33\%) male and 25 (41.67\%) female. Fifty-seven $(95 \%)$ patients had complete resection, as defined by macroscopically negative margins (R0/R1 resection) and three (5\%) had R2 resection. Twenty (33.33\%) patients had a second laparotomy and nine patients had a third laparotomy; all of them for locoregional recurrences. There was nil 90-day mortality following resection.

Twenty four patients $(40 \%)$ were younger than 55 years of age and $36(60 \%)$ were over 55 years of age. In $95 \%$ of the cases, tumor size was between $10-33 \mathrm{~cm}$ and only in $5 \%$ of tumors was size less than $5 \mathrm{~cm}$.

Most tumors (57\%) were of medium or high grade and the most common histological subtype was liposarcoma (59\%). Patient demographics and tumor characteristics are summarized in Table I. Information on resection type and margins are demonstrated in Table II. Irrespective of age, gender, tumor grade, size, and histological type, 90-day mortality postoperatively was zero. The operative details for all cases are described in Table III.

The median follow-up from time of operation (first time laparotomy) to endpoint date was 83 months. During the follow-up period, 26/60 patients $(43.33 \%)$ developed tumor recurrence (18 locally, four at a distant site and four both locally and distant). Twenty patients underwent a second laparotomy for locoregional recurrence, of whom 17 (85.0\%) had R0/R1 resection and three $(15.0 \%)$ had R2 resection. Within the group of patients with high-grade tumors, the recurrence rate was $51.5 \%$ compared with $20 \%$ in patients with low-grade tumors $(p=0.014)$. At last follow-up, 41 patients were alive, with only five of them presenting with evidence of recurrence. Two patients had died of unrelated causes, and 18 (30\%) head died from their disease. High-grade tumor was a statistically significant predictor of disease-related death (highvs. low-grade tumor: $14 / 35 v s .4 / 25 ; p=0.031$ ). 
Table I. Demographic and tumor characteristics of 60 patients with primary retroperitoneal sarcoma who underwent surgical treatment.

\begin{tabular}{lcc}
\hline Variable & $\mathrm{N}$ & $\%$ Of total \\
\hline Gender & & \\
$\quad$ Female & 25 & 41.67 \\
$\quad$ Male & 35 & 58.33 \\
Age & & \\
$\quad<55$ Years & 24 & 40.0 \\
$>55$ Years & 36 & 60.0 \\
Duration of symptoms & & \\
$\quad<3$ Months & 38 & 63.33 \\
$>3$ Months & 16 & 26.67 \\
$\quad$ Unknown & 6 & 10.0 \\
Histological subtype & & \\
Liposarcoma & 36 & 60 \\
Leiomyosarcoma & 10 & 16.67 \\
Malignant fibrous histiocytoma & 6 & 10.0 \\
Malignant peripheral nerve sheath tumor & 2 & 3.33 \\
Other & 6 & 10.0 \\
Tumor size (maximum diameter) & & \\
$\quad<5$ cm & 3 & 5.0 \\
$5-10 \mathrm{~cm}$ & 7 & 11.67 \\
10-20 cm & 26 & 43.33 \\
$\quad>20 \mathrm{~cm}$ & 24 & 40.0 \\
Tumor grade & & \\
Low & 25 & 41.67 \\
Medium/high & 35 & 58.33 \\
\hline
\end{tabular}

Both median DFS and median OS were not reached. Fiveand 10-year OS rates were $73 \%$ and $66 \%$ respectively (Figure 1a), whereas corresponding DFS rates were $65 \%$ and $59 \%$ respectively (Figure $1 \mathrm{~b}$ ). R2 resection [hazard ratio $(\mathrm{HR})=7.18,95 \%$ confidence interval $(\mathrm{CI})=1.50-34.22$; $p=0.013)$ and high-grade tumor $[\mathrm{HR}=3.50,95 \% \mathrm{CI}=1.15$ $10.65 ; p=0.027$ ) were significantly associated with decreased OS. In patients with low-grade tumors, 5- and 10-year OS rates were $88 \%$ and $79 \%$, respectively, while for these with high-grade tumors they were $56 \%$ and $39 \%$, respectively (Figure 2a). High-grade tumors were significantly associated with decreased DFS $(\mathrm{HR}=3.35 ; 95 \% \quad \mathrm{CI}=1.23-9.10$; $p=0.018)$. In patients with low-grade tumors, both 5- and 10year DFS rates were $80 \%$, while they were $53 \%$ and $43 \%$, respectively, in those with high-grade tumors (Figure $2 \mathrm{~b}$ ).

\section{Discussion}

Patients with RPS are usually diagnosed late, when the tumor is already of considerable size and close or attached to critical retroperitoneal structures and organs $(3,21)$. These constrains limit the surgeon's ability to perform wide resection with clear margins. Importantly, incomplete surgical resection comprises one of the greatest risk factors
Table II. Initial treatment characteristics of 60 patients with primary retroperitoneal sarcoma who underwent surgical treatment.

\begin{tabular}{lcc}
\hline Variable & $\mathrm{N}$ & $\%$ Of total \\
\hline Resection & & \\
R0/R1 & 57 & 95.0 \\
R2 & 3 & 5.0 \\
Contiguous organs resected & & \\
$\quad$ Yes & 44 & 73.33 \\
No & 16 & 26.67 \\
Compartmental organ resection & & \\
Yes & 4 & 6.67 \\
No & 56 & 93.33 \\
Radiation therapy & & \\
Preoperative & 0 & 0 \\
Intraoperative/postoperative & 0 & 0 \\
Both (preoperative and postoperative) & 0 & 0 \\
None & 60 & 100.00 \\
Chemotherapy & & \\
Neoadjuvant & 6 & 10.0 \\
Adjuvant & 10 & 16.67 \\
Both & 0 & 0 \\
None & 44 & 73.33 \\
\hline
\end{tabular}

Table III. Operative details of 60 patients with retroperitoneal sarcoma who underwent surgical treatment.

\begin{tabular}{lccc}
\hline Variable & $\begin{array}{c}\text { Total } \\
(\mathrm{N}=108), \\
\mathrm{n}(\%)\end{array}$ & $\begin{array}{c}\text { Primary } \\
(\mathrm{N}=60), \\
\mathrm{n}(\%)\end{array}$ & $\begin{array}{c}\text { Recurrent } \\
(\mathrm{N}=48), \\
\mathrm{n}(\%)\end{array}$ \\
\hline Complete resection & $101(93.5)$ & $55(94.8)$ & $46(95.8)$ \\
Multi-organ resection & $72(67)$ & $42(72.4)$ & $29(60)$ \\
Kidney & $22(30.5)$ & $14(24.1)$ & $8(27.2)$ \\
Colon & $17(23.5)$ & $7(10.3)$ & $9(30.6)$ \\
Pancreas & $7(9.7)$ & $4(6.9)$ & $3(10.2)$ \\
Small bowel & $8(11.1)$ & $5(8.6)$ & $4(13.6)$ \\
Duodenum & & & $1(3.4)$ \\
Adrenal gland & $4(5.6)$ & $3(5.2)$ & $2(6.8)$ \\
Bladder & $3(4.2)$ & $3(5.2)$ & $0(0)$ \\
Liver & $6(8.4)$ & $5(8.6)$ & $1(3.4)$ \\
Spleen & $3(4.2)$ & $3(5.2)$ & $1(3.4)$ \\
Diaphragm & $2(2.8)$ & $2(3.4)$ & $0(0)$ \\
Major vascular resection & $12(11.1)$ & $9(15.5)$ & $3(6.3)$ \\
IVC, abdominal aorta (infrarenal) & $7(6.5)$ & $5(8.6)$ & $2(4.2)$ \\
& & & $1(2.1)$ \\
Iliac artery & $2(1.9)$ & $2(3.4)$ & $0(0)$ \\
Iliac vein & $3(2.8)$ & $2(3.4)$ & $0(0)$ \\
Adjunct procedures & & & \\
Liver ablation & $7(6.5)$ & $3(5.2)$ & $1(2.1)$ \\
Angioembolization & $3(2.8)$ & $3(5.2)$ & $0(0)$ \\
IVC filter placement & $4(3.7)$ & $3(5.2)$ & $0(0)$ \\
Biliary stent & $2(1.9)$ & $1(1.7)$ & $0(0)$ \\
Ureteral stent & $33(30.1)$ & $18(31)$ & $10(20.8)$ \\
Femoral nerve monitoring & $2(1.9)$ & $0(0)$ & $2(4.2)$ \\
\hline
\end{tabular}

IVC: Inferior vena cava. 

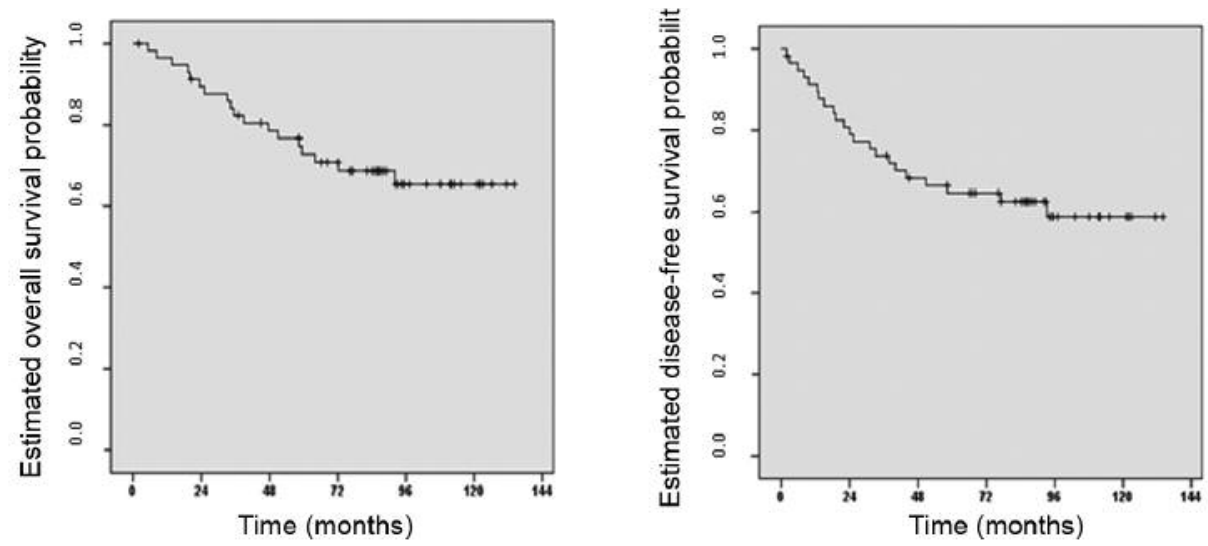

Figure 1. Kaplan-Meier curves for overall (a) and disease-free (b) survival. At 5 and 10 years, overall survival was $73 \%$ and $66 \%$, respectively, while disease-free survival was $65 \%$ and $59 \%$, respectively.
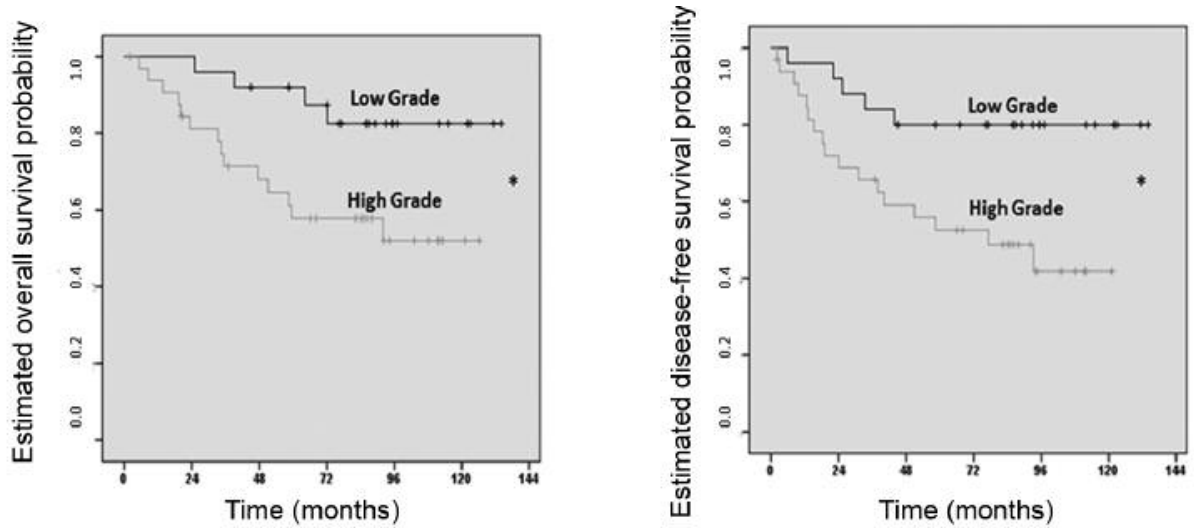

Figure 2. Kaplan-Meier curves for overall (a) and disease-free (b) survival based on tumor grade. At 5 and 10 years, overall survival was $88 \%$ and $79 \%$ in those with low-grade and $56 \%$ and $39 \%$ in those with high-grade tumors, respectively, *p=0.027. At 5 and 10 years, disease-free survival was $80 \%$ and $80 \%$ in those with low-grade and $53 \%$ and $43 \%$ in those with high-grade tumors, respectively, ${ }^{*} p=0.018$.

for early relapse and poor survival in patients with RPS (4, $16,17,19,21-24)$. It is, therefore, not surprising that management guidelines recommend that surgical resections should be undertaken at specialist sarcoma centers by surgeons with experience and expertise in such complex procedures $(4,22,25,26)$. Whilst in principle, we are in agreement with these recommendations, the reality in our countries dictates that the vast majority of patients diagnosed with these rare malignancies will be operated on at nonsarcoma specialist centers.

In this study, we report our experience on 69 patients with primary PRS who were operated on by general surgeons with experience in abdominal surgery of malignant tumors. They were supported by an MDT, but not by sarcoma specialists, who were following sarcoma management guidelines. The majority of these patients underwent fairly aggressively resection, comprising removal of the tumor en-bloc with surrounding organs adjacent to the tumor. This approach was well tolerated by the majority of patients, independent of their age and performance status. A combination of surgical techniques including complex and demanding techniques, such as full liver mobilization, subdiaphragmatic Inferior vena cava control, iliac dissection, vascular interpositions and organ revascularization were used when needed $(23,27,28)$.

Only four patients underwent a compartmental resection (liberal en bloc resection of non-involved tissues and neighboring organs) and this is because this approach was first introduced at our Institutions in 2010, that is, towards the end of the study period for this series (January 2002December 2016). Following many publications showing that this method is superior to simple resection (3-fold decrease 
in locoregional recurrence) $(13,17,18,23,29)$, we first performed this technique for a small subgroup of young patients with good performance status $(13,14)$. Since 2012 when an international consensus on the performance of surgery in RPS was reached, presented and standardized, this method has been increasingly used by our teams (data not included in this study) (30). The patients are of course informed about the potential morbidity of this procedure and the fact that there is a trend for survival benefit over contiguously involved organ resection (23). Simple resection is used with palliative rather than curative intent in the case of elderly patients with comorbidities, poor performance status and giant retroperitoneal tumors, who, a priori, are thought to have worse prognosis $(4,10)$.

The demographics of our study population are similar to those of other published series. Liposarcoma is the most common histology (59\%) followed by leiomyosarcoma (17\%) $(3,4,31)$, the majority of patients present with a tumor size between 10 and $33 \mathrm{~cm}$ and over half of all patients present with medium-/ high-grade tumors $(57 \%)(3,13,14,17,24$, $25,32,33)$. The prognostic significance of high tumor grade as predictor of recurrence $(p=0.014)$ and tumor related death $(p=0.031)$ was recorded, again in line with larger published series $(4,10,23,25,32)$. The adverse effect of incomplete resection $(\mathrm{R} 2)$ on $\mathrm{OS}$ was also reported $(\mathrm{HR}=3.50 ; 95 \%$ $\mathrm{CI}=1.15-10.65 ; p=0.027)$. With regards to recurrence rates, those reported in the literature range between $26 \%$ and $49 \%$ depending on the follow-up period $(16,25,31,34)$. The recurrence rate in our study over a follow-up period of 83 months was $43.33 \%$, which is in fact almost identical to the rates reported for other cohorts with similar or longer followup when using the same surgical approach (contiguously involved organ resection) $(25,29,31,34)$. Five-year DFS and OS rates were comparable to those previously reported by other surgical groups $(24,25,31,34,35)$.

The role of the MDT approach is highlighted in this study. Especially in patients with RPS, the input from specialists from different disciplines has been identified as a key factor in improving local control and patient survival $(4,36)$. The MDT work has been the cornerstone of the management of patients at our Institutions and has ensured compliance with guidelines, especially as we are at non-sarcoma specialist centers. Accurate diagnosis, careful preoperative planning, individualized patient management and input from specialists from different fields in a multidisciplinary context have been fundamental in preserving a high quality service for our patients. This close working relationship between the team members alongside evidence based practice and adherence to guidelines are, in our view, the reasons why our outcomes are comparable to those of high-volume centers and the morbidity rates are low.

The limitations of this being retrospective study with a relatively small number of patients are acknowledged.

\section{Conclusion}

Complete resection of RPS represents the mainstay among all available therapeutic methods. In the form of contiguous organ resection or as compartmental resection of noninvolved contiguous organs, this procedure is radical, and in the hands of experienced surgeons, it might provide better outcomes in terms of local control and improved survival compared to simple resection, without significant increase in morbidity or mortality. Our study adds further evidence to support this practice. Although sarcoma expertise may not always be available, skilled surgeons with experience in surgical oncology who adhere to international sarcoma guidelines and work within an MDT setting may still achieve similar clinical outcomes, offering their patients high chances for long survival. It is, therefore, important that for rare diseases such as RPS, specialists working in highvolume centers share their knowledge by providing evidence and comprehensive guidance on treatments that are critical for the survival of their patients.

\section{Competing Interests}

The Authors declare that they have no competing interests.

\section{Conflicts of Interest}

None.

\section{Funding}

None.

\section{References}

1 Gutierrez JC, Perez EA, Franceschi D, Moffat FL Jr., Livingstone AS and Koniaris LG: Outcomes for soft-tissue sarcoma in 8249 cases from a large state cancer registry. J Surg Res 141(1): 105-114, 2007.

2 Messiou C, Moskovic E, Vanel D, Morosi C, Benchimol R, Strauss D, Miah A, Douis H, van Houdt W and Bonvalot S: Primary retroperitoneal soft-tissue sarcoma: Imaging appearances, pitfalls and diagnostic algorithm. Eur J Surg Oncol, 2016. pii: S0748-7983(16)31010-1. doi: 10.1016/j.ejso.2016. 10.032. [Epub ahead of print]

3 Thomas DM, O'Sullivan B and Gronchi A: Current concepts and future perspectives in retroperitoneal soft-tissue sarcoma management. Expert Rev Anticancer Ther 9(8): 1145-1157, 2009.

4 von Mehren M, Randall RL, Benjamin RS, Boles S, Bui MM, Conrad EU, 3rd, Ganjoo KN, George S, Gonzalez RJ, Heslin MJ, Kane JM, 3rd, Koon H, Mayerson J, McCarter M, McGarry SV, Meyer C, O'Donnell RJ, Pappo AS, Paz IB, Petersen IA, Pfeifer JD, Riedel RF, Schuetze S, Schupak KD, Schwartz HS, Tap WD, Wayne JD, Bergman MA and Scavone J: Soft-tissue sarcoma, version 2.2016, NCCN Clinical Practice Guidelines in Oncology. J Natl Compr Canc Netw 14(6): 758-786, 2016. 
5 Singer S, Corson JM, Demetri GD, Healey EA, Marcus K and Eberlein TJ: Prognostic factors predictive of survival for truncal and retroperitoneal soft-tissue sarcoma. Ann Surg 221(2): 185195, 1995.

6 Heslin MJ, Lewis JJ, Nadler E, Newman E, Woodruff JM, Casper ES, Leung D and Brennan MF: Prognostic factors associated with long-term survival for retroperitoneal sarcoma: Implications for management. J Clin Oncol 15(8): 2832-2839, 1997.

7 Dalal KM, Kattan MW, Antonescu CR, Brennan MF and Singer S: Subtype-specific prognostic nomogram for patients with primary liposarcoma of the retroperitoneum, extremity, or trunk. Ann Surg 244(3): 381-391, 2006

8 Raut CP and Pisters PW: Retroperitoneal sarcomas: Combinedmodality treatment approaches. J Surg Oncol 94(1): 81-87, 2006.

9 Le Pechoux C, Musat E, Baey C, Al Mokhles H, Terrier P, Domont J, Le Cesne A, Laplanche A and Bonvalot S: Should adjuvant radiotherapy be administered in addition to front-line aggressive surgery (FAS) in patients with primary retroperitoneal sarcoma? Ann Oncol 24(3): 832-837, 2013.

10 Giuliano K, Nagarajan N, Canner JK, Wolfgang CL, Bivalacqua T, Terezakis S, Herman J, Schneider EB and Ahuja N: Predictors of improved survival for patients with retroperitoneal sarcoma. Surgery 160(6): 1628-1635, 2016.

11 Nussbaum DP, Rushing CN, Lane WO, Cardona DM, Kirsch DG, Peterson BL and Blazer DG, 3rd: Preoperative or postoperative radiotherapy versus surgery alone for retroperitoneal sarcoma: A case-control, propensity scorematched analysis of a nationwide clinical oncology database. Lancet Oncol 17(7): 966-975, 2016.

12 Yu JI, Lim DH, Park HC, Nam H, Kim BK, Kim SJ and Park JB: Clinical outcomes of tissue expanders on adjuvant radiotherapy of resected retroperitoneal sarcoma. Medicine (Baltimore) 95(28): e4123, 2016.

13 Gronchi A, Lo Vullo S, Fiore M, Mussi C, Stacchiotti S, Collini P, Lozza L, Pennacchioli E, Mariani L and Casali PG: Aggressive surgical policies in a retrospectively reviewed singleinstitution case series of retroperitoneal soft-tissue sarcoma patients. J Clin Oncol 27(1): 24-30, 2009.

14 Bonvalot S, Rivoire M, Castaing M, Stoeckle E, Le Cesne A, Blay JY and Laplanche A: Primary retroperitoneal sarcomas: A multivariate analysis of surgical factors associated with local control. J Clin Oncol 27(1): 31-37, 2009.

15 van Doorn RC, Gallee MP, Hart AA, Gortzak E, Rutgers EJ, van Coevorden F, Keus RB and Zoetmulder FA: Resectable retroperitoneal soft-tissue sarcomas. The effect of extent of resection and postoperative radiation therapy on local tumor control. Cancer 73(3): 637-642, 1994.

16 Stahl JM, Corso CD, Park HS, An Y, Rutter CE, Han D and Roberts KB: The effect of microscopic margin status on survival in adult retroperitoneal soft-tissue sarcomas. Eur J Surg Oncol 43(1): 168-174, 2017.

17 Doepker MP, Hanna KH, Thompson ZJ, Binitie OT, Letson DG and Gonzalez RJ: Recurrence and survival analysis of resected soft-tissue sarcomas of pelvic retroperitoneal structures. J Surg Oncol 113(1): 103-107, 2016.

18 Bonvalot S, Miceli R, Berselli M, Causeret S, Colombo C, Mariani L, Bouzaiene H, Le Pechoux C, Casali PG, Le Cesne $\mathrm{A}$, Fiore $\mathrm{M}$ and Gronchi A: Aggressive surgery in retroperitoneal soft-tissue sarcoma carried out at high-volume centers is safe and is associated with improved local control. Ann Surg Oncol 17(6): 1507-1514, 2010.

19 McBride SM, Raut CP, Lapidus M, Devlin PM, Marcus KJ, Bertagnolli M, George S and Baldini EH: Locoregional recurrence after preoperative radiation therapy for retroperitoneal sarcoma: Adverse impact of multifocal disease and potential implications of dose escalation. Ann Surg Oncol 20(7): 2140-2147, 2013.

20 Raut CP, Miceli R, Strauss DC, Swallow CJ, Hohenberger P, van Coevorden F, Rutkowski P, Fiore M, Callegaro D, Casali PG, Haas RL, Hayes AJ, Honore C, Cannell AJ, Jakob J, Szacht M, Fairweather M, Pollock RE, Bonvalot S and Gronchi A: External validation of a multi-institutional retroperitoneal sarcoma nomogram. Cancer 122(9): 1417-1424, 2016.

21 Strauss DC, Hayes AJ, Thway K, Moskovic EC, Fisher C and Thomas JM: Surgical management of primary retroperitoneal sarcoma. Br J Surg 97(5): 698-706, 2010.

22 Abdelfatah E, Guzzetta AA, Nagarajan N, Wolfgang CL, Pawlik TM, Choti MA, Schulick R, Montgomery EA, Meyer C, Thornton K, Herman J, Terezakis S, Frassica D and Ahuja N: Long-term outcomes in treatment of retroperitoneal sarcomas: A 15 year single-institution evaluation of prognostic features. J Surg Oncol 114(1): 56-64, 2016.

23 Garcia-Ortega DY, Villa-Zepeda O, Martinez-Said H, CuellarHubbe $M$ and Luna-Ortiz $\mathrm{K}$ : Oncology outcomes in retroperitoneal sarcomas: Prognostic factors in a retrospective cohort study. Int J Surg 32: 45-49, 2016.

24 Chou YS, Liu CY, Chang YH, King KL, Chen PC, Pan CC, Shen SH, Liu YM, Lin AT, Chen KK, Shyr YM, Lee RC, Chao TC, Yang MH, Chan CH, You JY and Yen CC: Prognostic factors of primary resected retroperitoneal soft-tissue sarcoma: Analysis from a single asian tertiary center and external validation of gronchi's nomogram. J Surg Oncol 113(4): 355$360,2016$.

25 Gronchi A, Strauss DC, Miceli R, Bonvalot S, Swallow CJ, Hohenberger P, Van Coevorden F, Rutkowski P, Callegaro D, Hayes AJ, Honore C, Fairweather M, Cannell A, Jakob J, Haas RL, Szacht M, Fiore M, Casali PG, Pollock RE and Raut CP: Variability in patterns of recurrence after resection of primary retroperitoneal sarcoma (rps): A report on 1007 patients from the multi-institutional collaborative rps working group. Ann Surg 263(5): 1002-1009, 2016.

26 Trans-Atlantic RPSWG: Management of recurrent retroperitoneal sarcoma (rps) in the adult: A consensus approach from the trans-atlantic rps working group. Ann Surg Oncol 23(11): 3531-3540, 2016.

27 Georgopoulos S, Felekouras E, Markatis F, Karles D, Klonaris C, Bakoyiannis C, Pikoulis E, Bastounis E and Papalambros E: Retroperitoneal tumor invasion of the inferior vena cava. A single-centre experience in tumor thrombectomy. Acta Biomed 81(3): 185-188, 2010.

28 Petrou A, Kontos M, Prassas E, Bramis K, Papalambros A, Brennan N, Mihas C and Felekouras E: The three-surgeon technique for liver tissue dissection: Towards real bloodless hepatectomy. J BUON 17(2): 304-309, 2012.

29 Gronchi A, Miceli R, Colombo C, Stacchiotti S, Collini P, Mariani L, Sangalli C, Radaelli S, Sanfilippo R, Fiore M and Casali PG: Frontline extended surgery is associated with improved survival in retroperitoneal low- to intermediategrade soft-tissue sarcomas. Ann Oncol 23(4): 1067-1073, 2012 . 
30 Bonvalot S, Raut CP, Pollock RE, Rutkowski P, Strauss DC, Hayes AJ, Van Coevorden F, Fiore M, Stoeckle E, Hohenberger $\mathrm{P}$ and Gronchi A: Technical considerations in surgery for retroperitoneal sarcomas: Position paper from e-surge, a master class in sarcoma surgery, and eortc-stbsg. Ann Surg Oncol 19(9): 2981-2991, 2012.

31 Konofaos P, Spartalis E, Moris D, Athanasiou A, Dimitroulis D, Markakis C, Kostakis ID, Nikiteas $\mathrm{N}$ and Kouraklis G: Challenges in the surgical treatment of retroperitoneal sarcomas. Indian J Surg 78(1): 1-5, 2016.

32 Lehnert T, Cardona S, Hinz U, Willeke F, Mechtersheimer G, Treiber M, Herfarth C, Buechler MW and Schwarzbach MH: Primary and locally recurrent retroperitoneal soft-tissue sarcoma: Local control and survival. Eur J Surg Oncol 35(9): 986-993, 2009.

33 Hassan I, Park SZ, Donohue JH, Nagorney DM, Kay PA, Nasciemento AG, Schleck CD and Ilstrup DM: Operative management of primary retroperitoneal sarcomas: A reappraisal of an institutional experience. Ann Surg 239(2): 244-250, 2004.
34 Hamilton TD, Cannell AJ, Kim M, Catton CN, Blackstein ME, Dickson BC, Gladdy RA and Swallow CJ: Results of resection for recurrent or residual retroperitoneal sarcoma after failed primary treatment. Ann Surg Oncol 24(1): 211-218, 2017.

35 Pierie JP, Betensky RA, Choudry U, Willett CG, Souba WW and Ott MJ: Outcomes in a series of 103 retroperitoneal sarcomas. Eur J Surg Oncol 32(10): 1235-1241, 2006.

36 Strauss DC, Hayes AJ and Thomas JM: Retroperitoneal tumours: Review of management. Ann R Coll Surg Engl 93(4): 275-280, 2011.
Received February 10, 2017

Revised March 6, 2017

Accepted March 10, 2017 